\title{
The silence of patients with end-stage COPD: a qualitative study
}

\author{
Jolanda M Habraken, Jeannette Pols, Patrick JE Bindels, Dick L Willems
}

\begin{abstract}
\section{Background}

Patients with end-stage chronic obstructive pulmonary disease (COPD) experience poor quality of life and considerable problems in daily life. However, as they often do not actively express a wish for help, they do
\end{abstract} not get the help they need.

Aim

To gain insight into why patients with end-stage COPD tend not to express a wish for help.

\section{Design of study}

Prospective qualitative study with semi-structured interviews.

Setting

Outpatient clinics of four hospitals and one centre specialising in asthma and COPD in the Netherlands.

\section{Method}

Sixteen semi-structured interviews were conducted with 11 patients with end-stage COPD.

\section{Results}

To express a wish for help, patients should regard their limitations as abnormal and should realise that there are possibilities to improve their situation. However, this was not the case with the patients interviewed. They appeared to consider themselves ill at a time of acute exacerbation of their illness, but regarded their everyday life as normal. In addition, patients lived with the assumption that, as their lungs were damaged beyond repair, they could not get help.

\section{Conclusion}

Patients with end-stage COPD do not actively express a wish for help because they do not consider their limitations to be abnormal and because they do not realise that there are possibilities to improve their situation. These results suggest that care in this stage of the disease should focus on improving daily life instead of just aiming to improve the functioning of the lungs. Professionals in health care should actively explore what kind of practical help these patients might welcome in keeping up their daily activities. Future research should focus on studying whether such an approach applies to the needs of patients with endstage COPD.

\section{Keywords}

chronic disease; palliative care; patient-centered care; primary health care; pulmonary disease, chronic obstructive; qualitative research.

\section{INTRODUCTION}

End-stage chronic obstructive pulmonary disease (COPD) follows a typical illness trajectory of long-term limitations with intermittent serious episodes, as described by Murray et al. ${ }^{1}$ Patients with end-stage COPD are usually ill for a long period of time with occasional acute exacerbations. Although these exacerbations are severe and may result in death, patients usually survive many such episodes. ${ }^{2}$

Studies in patients with end-stage COPD have shown that many experience poor quality of life and considerable problems in daily life. Most problems arise from breathlessness ${ }^{3-7}$ as this often leads to immobility, ${ }^{4}$ dependency on others, ${ }^{5}$ and social isolation. ${ }^{7,8}$ Anxiety and depression are also common. ${ }^{9-11}$

It could be expected that patients with such impairments have numerous preferences, wants, and demands regarding how their situation could be improved. However, as part of a larger study on care for patients with end-stage COPD using in-depth interviews with patients, indications were found that patients did not actively express a wish for help, even though they experienced numerous limitations in their daily lives: they remained silent. To gain insight into this silence, the current study's research question was: 'Why do patients with end-stage COPD not actively express a wish for help?'

JM Habraken, MSc, researcher; J Pols, PhD, postdoc researcher; PJE Bindels, $M D, P h D$, professor of general practice; $D L$ Willems, $M D, P h D$, professor of medical ethics, Department of General Practice, Academic Medical Center, University of Amsterdam, The Netherlands.

Address for correspondence

Jolanda M Habraken, Clinical Methods and Public Health, Department of General Practice, Medical Ethics, Academic Medical Center, University of Amsterdam, Meibergdreef 15, 1105 AZ Amsterdam, The Netherlands. E-mail: j.m.habraken@amc.uva.nl

Submitted: 16 May 2008; Editor's response: 16 July 2008; final acceptance: 10 October 2008.

(c)British Journal of General Practice 2008; 58: 844-849.

DOI: 10.3399/bjgp08X376186 


\section{METHOD}

\section{Setting and participants}

Responders were identified from a sample of patients with COPD collected for a previous quantitative study that employed written quality-of-life questionnaires in 2004-2006 in the Netherlands. ${ }^{12}$ In that study, 82 patients with Global Initiative for Chronic Obstructive Lung Disease (GOLD) stage IV (defined as forced expiratory volume in 1 second $<30 \%$ of predicted) COPD who were aged 60 years or older were recruited randomly from outpatient clinics of four participating hospitals and one centre specialising in asthma and COPD in the Netherlands. Patients received a quality-of-life questionnaire every 3 months, for a maximum period of 1 year in total.

From those 82 patients with end-stage COPD, 11 responders were selected for the present qualitative study. The sampling was done purposefully to ensure that a wide variety of patients' experiences was recorded. A mix of male and female patients, patients living alone and living with their partner, and patients with and without long-term oxygen therapy were selected. Patients were included until data about the lack of expressed wish for help reached saturation. All patients provided informed consent.

\section{Interviews}

Semi-structured in-depth interviews were performed by one researcher at each patient's home and lasted 1.5-2.5 hours. The aim of the interviews was to provide an in-depth viewpoint based on personal experience. This was done by using open-ended questions that were guided by a list of topics such as activities of daily living, medical and informal care, social support, stigmatisation, anxiety, and future. The interview process was iterative and the topic list evolved over time. For example, help-seeking behaviour was initially not one of the topics on the list, but was added after conducting the first few

\section{How this fits in}

Patients with end-stage chronic obstructive pulmonary disease (COPD)

experience numerous problems in daily life, yet they do not often actively

express a wish for help because they do not regard themselves as ill, and

because they do not feel that their situation can be improved. The results in this

paper suggest that care for patients with end-stage COPD should focus on

improving daily life, instead of solely focusing on the improvement of lung

function. Professionals in health care should aim to explore actively what

practical help these patients would welcome in keeping up their normal daily

activities. Future research should be directed towards studying whether such an

approach meets the needs of patients at this stage of COPD.

interviews, when it became apparent that patients did not actively express their wishes for help. The first question in every interview was: 'Can you describe a normal day?'. All interviews were audio-taped and fully transcribed.

\section{Data analysis}

The analyses were done by two researchers using MAXQDA (VERBI software, Berlin) and consisted of multiple phases largely based on Pope et al's recommendations for qualitative research. ${ }^{13}$ To get a feeling of what the patients had said about the topics, one researcher worked through the interviews deductively using the primary topic list (the familiarisation phase). After this, the analyses continued in a more inductive way to include other aspects, such as living with physical limitations and the relationship with others, as these subjects were frequently mentioned by the patients.

Recurrent themes within the transcripts were then identified and text fragments were sorted. Discussion between all authors led to the arrangement of categories and themes. As a result, a thematic framework was constructed, consisting of categories and themes, as shown in Figure 1.

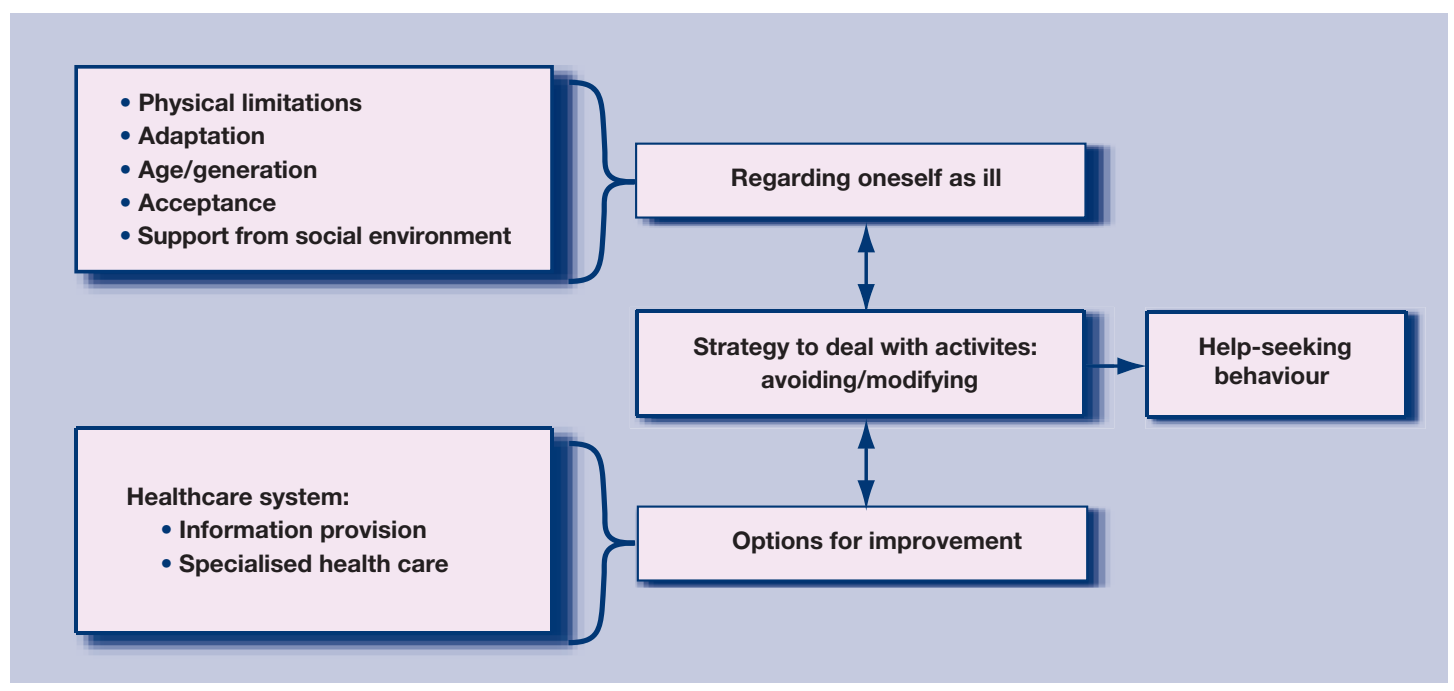

Figure 1. Thematic framework. 


\section{RESULTS}

In total, 16 interviews with 11 patients were conducted by a researcher during a period of 2 years (2004-2006). Five patients were interviewed again after 6 months; for example because the first interview did not cover all topics from the topic list, or because something changed in the patient's situation. It was possible to monitor patients' progress because of the longitudinal aspect of the original study, in which patients received a questionnaire every 3 months. Patient characteristics are highlighted in Table 1; all patient names are fictitious.

\section{Experienced limitations}

Before gaining an understanding of the silence of patients with end-stage COPD, the nature of the limitations they experience in daily life must be considered, as discussed in the interviews. Breathlessness was the most apparent physical limitation:

I'm a lucky man whenever I wake up in the morning and l'm not breathless. When that happens, I stay in bed for a while to enjoy it. But only until I need to go to the toilet. That's where the trouble starts, where the first breathlessness starts. After I'm finished, I come back to the bedroom and take oxygen for about 10 minutes.' (John)

Anxiety was also common. Patients described that it is scary when they are unable to get control of their breathing. Sometimes, when they experienced severe breathlessness, they were afraid they would suffocate:

I'm not afraid of anything, except for suffocation. I've experienced the beginning of suffocation twice, and I really don't want that to be my ending!' (Gerard)

Table 1. Patient characteristics.

\begin{tabular}{lccccc} 
Code name & Age, years & Sex & $\begin{array}{c}\text { Marital } \\
\text { status }\end{array}$ & $\begin{array}{c}\text { Dependent } \\
\text { on oxygen }\end{array}$ & $\begin{array}{c}\text { Number of } \\
\text { interviews }\end{array}$ \\
\hline Anton & 70 & Male & Married & No & 2 \\
\hline Ben & 74 & Male & Married & Yes & 1 \\
\hline Charlotte & 81 & Female & Single & No & 1 \\
\hline Debby & 61 & Female & Married & No & 2 \\
\hline Edward & 72 & Male & Widowed & No & 2 \\
\hline Fiona & 72 & Female & Widowed & No & 1 \\
\hline Gerard & 64 & Male & Married & Yes & 2 \\
\hline Harry & 74 & Male & Single & No & 1 \\
\hline lan & 65 & Male & Married & No & 1 \\
\hline John & 83 & Male & Married & Yes & 2 \\
\hline Kevin & 69 & Male & Married & No & 1 \\
\hline
\end{tabular}

'When you get breathless, that's not ... that's not pleasant you know. I used to say "I'd rather spend a week in jail than spend one day in hospital". That's what I used to say, but now ... l've been taken to hospital three times by ambulance because I was breathless. And when that happens, you're glad that they take you to hospital!' (Kevin)

Social limitations became evident when patients became less mobile as a result of their physical limitations. Sometimes, they did not leave their house for months, especially during winter because of bad weather conditions. Another reason mentioned was the increased risk of catching a cold that might turn into pneumonia.

'In summer he can go out and sit in the garden for a bit, but in winter, it's mostly indoors.' (lan's partner)

'Last winter, I didn't go out at all.' (Anton)

\section{Coping strategies}

To cope with their limitations, patients appeared to adopt one of two strategies:

- Strategy 1: to continue doing daily activities by modifying them; for example, taking breaks in between activities, or using aids and appliances. This enabled patients to keep up their physical condition and allowed them to spend time outside the house, which are necessary to maintain independence and a certain degree of social life.

- Strategy 2: to avoid activities altogether, instead of finding new ways to continue doing the activities they were used to.

Some responders used strategy 1, but most responders avoided activities:

'After the laundry was done, I used to hang it up immediately. I just put everything on the ground, and I had to bend over a lot. Now, I put the laundry basket on top of something else so I don't have to bend over so much.' (Debby, strategy 1)

Anton: 'I would like to be able to go to the shopping mall, but that takes so much energy, so much energy, that it would have to be really necessary. Otherwise, I don't go there.' (strategy 2) Interviewer: 'Your life is really here, at home?' Anton: 'Yes.'

'We used to go walking a lot. We just can't do it anymore because after about 100 metres I get out 
of breath. So, we don't do it anymore. There's no joy in that anymore.' (lan, strategy 2)

'If I'm honest, I have to say that I live in that chair for $99 \%$ of the time.' (John, strategy 2)

When patients stop being active, they tend to become more and more dependent on people in their close environment for their daily functioning. However, even those who spent most of their time inside their house still did not actively seek help.

\section{Conditions for asking for help}

To be able to ask for help, as is often required for healthcare provision in modern medicine, two conditions have to be met:

- patients need to regard the limitations they experience as something out of the ordinary and a reason to go and seek help; and

- patients need to know that their situation may be improved.

From these interviews it became clear that both conditions were not met in most cases.

\section{'I have COPD but, apart from that, I am not ill'}

The first condition to be able to ask for help was that patients needed to regard their limitations as abnormal. However, many of the patients interviewed did not feel that having limitations was the same as being ill. They appeared to consider themselves ill at a time of acute exacerbation of their illness, like an infection, or at any time when they were in hospital, but regarded their everyday life as normal:

'We're not really ill. It may sound funny, but a COPD patient is not ill. He is breathless. Whenever I get an infection, a bacterium, then I'm ill. But like now, I'm not ill because I can eat properly, I can still laugh, I still have fun in my life.' (Gerard)

Three reasons for not seeing oneself as ill were identified from the interviews. Patients with COPD spend a relatively long time in the end-stage of their illness, compared with illnesses with a different disease trajectory such as cancer. They adapt to their deteriorating health status because they have time to adjust to relatively small deteriorations and time to become used to their limitations. As a result, a life with limitations becomes normal:

'It just goes so slowly. We don't really notice but other people do. They see that he can no longer do things that he could a year ago. For us it's just normal.' (lan's partner)
In addition to adapting to their limitations, patients compared themselves to other people of their own age. They found that most people their age had one or more chronic illness and used some kind of medication. Therefore, in comparison with others, patients with end-stage COPD regarded their limitations as an unavoidable part of ageing, instead of something unusual or undesirable.

'These lungs won't get any better. That's something you need to accept. Well, compared to other people ... everyone has got something at my age! I feel lucky to have what I have.' (Charlotte)

The way patients were viewed by others appeared to contribute to the way they perceived their limitations as something to live with, instead of something to seek help for. As their illness affects the lungs, it is less visible; as such, although they experience limitations, people in their environment fail to recognise that they are suffering from an illness. Without recognition and encouragement from their environment, patients did not feel that what they had was something to seek help for.

On occasion, they even experienced negative reactions from their environment:

'It's hard to explain. Sometimes, I am working in the garden without any problems. After a while, I come into the house and boom, it's over. Suddenly I'm exhausted, I can't do anything. That's hard to explain. She [my wife] sometimes doesn't understand. But I don't even understand! Because one moment, l'm working and the next, I can't do anything anymore. It's hard to explain because you can't see any difference, I still look the same.' (Anton)

The first condition that was needed for patients to be able to ask for help was not met; that is, patients did not regard the limitations they experienced as something out of the ordinary. The second condition, that patients should be aware that there are possibilities to improve their situation, was investigated.

\section{'I cannot be helped'}

Patients in this study were seeing a respiratory physician on a regular basis, mostly once or twice a year. As well as these visits to the respiratory physician, they were all seeing their GP. However, as they were already seeing a specialist regarding these issues, they did not always discuss their lung problems with their GP:

Interviewer: 'Is your GP involved in the care for your lungs?' 


\begin{abstract}
Anton: 'No. I'm seeing a respiratory physician ...'
I visit the respiratory physician once a year, and when I'm really ill I go and see my GP. But that can be about something completely different. We don't discuss my emphysema then. It's registered somewhere, emphysema, but we don't talk about it.' (lan)
\end{abstract}

The extent to which patients know or expect that their situation can be improved is dependent on the information they get regarding possible treatments. During the interviews patients explained that their conversations with the respiratory physician were mostly about the condition of their lungs. Patients said they were told that their lungs would only get worse, and that they would have to deal with that. More importantly, they were told there was nothing more the respiratory physician could do for them. Patients often talked about their illness in these same terms:

'Well, the X-rays were good. I don't know what good means, but eh, well, something that's broke cannot be fixed. At least not with lungs.' (Ian)

Patients lived with the assumption that, as their lungs were damaged beyond repair, they could not get help, and stated that both they and their physicians failed to discuss the limitations experienced in daily life and how these might be improved. It is likely that when doctors discuss daily activities with their patients, they would probably advise patients to be more active; however, because breathlessness increases with activity, being more active may feel scary for patients. Such advice would, therefore, not automatically improve the situation.

According to the responders, despite their wondering about the course of the illness and what they could expect for the future, these issues were also hardly ever discussed with their physician. As a result, they drew their own conclusions, which were not always optimistic:

'I make calculations. Before, my lung function was $35 \%$, and 2 years later it was $5 \%$ less. So, I calculate a loss of $5 \%$ every 2 years. That means that after 4 or 5 years, grandpa will be gone.' (Kevin)

Patients with end-stage COPD believed that they could not be helped; as such, the second condition of asking for help was not met. In other words, patients were not aware that there are possibilities to improve their situation.

\section{DISCUSSION}

\section{Summary of main findings}

The patients with end-stage COPD in this study experienced numerous limitations in their everyday lives. They did not always succeed in keeping up their daily activities, and sometimes avoided certain activities when these became too burdensome. Despite this, they did not actively express a wish for help because they did not regard their limitations as abnormal and they did not realise that there are possibilities to improve their situation.

\section{Strengths and limitations of the study}

This study adds to the limited body of knowledge about the end stage of COPD and the way patients experience their illness. The qualitative method used in this study is important for exploring patients' experiences, opinions, and their daily lives. The possibility to return to the patient for further information is another strength of the study. Some difficulties were encountered in conducting the interviews because some patients had difficulties expressing themselves verbally. They sometimes had trouble in verbalising their wishes and desires, even when they were directly asked to do so. However, this method proved valid as it was possible to extract the reasons for the absence of expressed wishes and desires, also described as the silence of the COPD patients.

A limitation of the study is that, even though data saturation was reached concerning the lack of expressed wish for help, the researchers cannot be completely sure that in a different group of patients exactly the same results would be found. Therefore, a replication of this study is warranted to see whether the current results are found elsewhere. If so, a followup quantitative study is needed to explore the actual percentage of patients in this stage that fail to request any help.

\section{Comparison with existing literature}

Although the body of literature about the end stage of COPD is limited, there are publications that have reported on the poor quality of life experienced by patients in this stage. ${ }^{14-15}$ Studies report on the severe physical symptoms patients experience (mostly breathlessness), ${ }^{6,8,9,16}$ and also on psychological and social symptoms, such as anxiety, ${ }^{6,9,16}$ depression, ${ }^{6,9,16}$ and social isolation. ${ }^{8,17}$

Jones et $a^{5}$ also reported that many patients would not express needs even when prompted. This is consistent with the current findings that patients do not know that there are options to improve their situation. The authors suggested that this might be related to an unwillingness to appear ungrateful. The current findings further elaborate on and analyse this silence of patients who have COPD. 
Others have reported similar findings about helpseeking behaviour in people who have other chronic illnesses associated with older age. Sanders et al reported that patients with chronic arthritis, who had experienced pain and disability for decades, perceived their symptoms as being inevitable and associated with normal ageing. They were also pessimistic about formal care. ${ }^{18}$ Pound et al explored why older patients responded to a stroke as something that was 'not that bad' within the theory of biographical disruption. ${ }^{19}$ This is consistent with the current findings that patients do not consider themselves to be ill. In a literature review, Koch described that very few women with urinary incontinence seek help. She found that, among other factors, the belief that urinary incontinence is a normal result of ageing affected help-seeking behaviour. $^{20}$

\section{Implications for clinical practice and future research}

Although there is consensus that patients with endstage COPD have impaired quality of life, they do not receive appropriate help from healthcare institutions. Results of this study indicate that patients experience problems in conducting their daily activities. However, this study also indicates that these problems are rarely discussed with the treating physician (GP or respiratory physician). Therefore, it may be assumed that the care of patients with end-stage COPD should focus on improving activities of daily living instead of only aiming to improve lung function.

Supporting and teaching care focusing on daily life is already applied by physical therapists in pulmonary rehabilitation programmes, which have proved to be successful even in patients with very severe COPD. ${ }^{21,22}$ As well as offering advice, this care actively supports patients in learning to keep up their daily activities by teaching them how to use breathing techniques, how to dose their energy, and how to use appropriate aids and appliances. The current study's results suggest that patients with end-stage COPD may benefit from this type of supporting care focusing on daily life. Healthcare providers should actively explore what practical help these patients might welcome in sustaining normal daily activity.

Future research should aim to study whether such an approach meets the needs of patients with endstage COPD.

\section{Funding}

This research was funded by the Netherlands Asthma Foundation (3.4.02.21)

\section{Ethical approval}

All patients provided written informed consent. The research ethics committee of the Amsterdam Medical Center (AMC) reviewed the protocol. It judged that the study did not meet the criteria for formal ethical review, as it consisted of interviews only. Therefore, this study did not have to be formally evaluated by the AMC's research ethics committee

\section{Competing interests}

The authors have stated that there are none

\section{Acknowledgements}

The authors would like to thank all patients who participated in this research for their time and efforts.

\section{Discuss this article}

Contribute and read comments about this article on the Discussion Forum: http://www.rcgp.org.uk/bjgp-discuss

\section{REFERENCES}

1. Murray SA, Kendall M, Boyd K, Sheikh A. Illness trajectories and palliative care. BMJ 2005; 330(7498): 1007-1011.

2. Viegi G, Pistelli F, Sherrill DL, et al. Definition, epidemiology and natural history of COPD. Eur Respir J 2007; 30(5): 993-1013

3. Claessens MT, Lynn J, Zhong Z, et al. Dying with lung cancer or chronic obstructive pulmonary disease: insights from SUPPORT. Study to Understand Prognoses and Preferences for Outcomes and Risks of Treatments. J Am Geriatr Soc 2000; 48(5 Suppl): S146-S153.

4. Elkington $\mathrm{H}$, White $\mathrm{P}$, Addington-Hall J, et al. The last year of life of COPD: a qualitative study of symptoms and services. Respir Med 2004; 98(5): 439-445.

5. Jones I, Kirby A, Ormiston P, et al. The needs of patients dying of chronic obstructive pulmonary disease in the community. Fam Pract 2004; 21(3): 310-313.

6. Robinson T. Living with severe hypoxic COPD: the patients' experience. Nurs Times 2005; 101(7): 38-42.

7. Skilbeck J, Mott L, Page $\mathrm{H}$, et al. Palliative care in chronic obstructive airways disease: a needs assessment. Palliat Med 1998; 12(4): 245-254.

8. Ek K, Ternestedt BM. Living with chronic obstructive pulmonary disease at the end of life: a phenomenological study. J Adv Nurs 2008; 62(4): 470-478.

9. Gore JM, Brophy CJ, Greenstone MA. How well do we care for patients with end stage chronic obstructive pulmonary disease (COPD)? A comparison of palliative care and quality of life in COPD and lung cancer. Thorax 2000; 55(12): 1000-1006.

10. Bailey PH. The dyspnea-anxiety-dyspnea cycle - COPD patients' stories of breathlessness: "It's scary /when you can't breathe". Qual Health Res 2004; 14(6): 760-778.

11. Curtis JR. Palliative and end-of-life care for patients with severe COPD. Eur Respir J 2008; 32(3): 796-803.

12. Habraken JM, Ter Riet G, Gore JM, et al. Health-related quality of life in end stage COPD and lung cancer. J Pain Symptom Manage 2008; in press.

13. Pope C, Ziebland S, Mays N. Qualitative research in health care. Analysing qualitative data. BMJ 2000; 320(7227): 114-116.

14. Goodridge D. People with chronic obstructive pulmonary disease at the end of life: a review of the literature. Int J Palliat Nurs 2006; 12(8): 390-396.

15. Habraken JM, Willems DL, de Kort SJ, Bindels PJ. Health care needs in end-stage COPD: a structured literature review. Patient Educ Couns 2007; 68(2): 121-130.

16. Peruzza S, Sergi G, Vianello A, et al. Chronic obstructive pulmonary disease (COPD) in elderly subjects: impact on functional status and quality of life. Respir Med 2003; 97(6): 612-617.

17. Seamark DA, Blake SD, Seamark CJ, Halpin DM. Living with severe chronic obstructive pulmonary disease (COPD): perceptions of patients and their carers. An interpretative phenomenological analysis. Palliat Med 2004; 18(7): 619-625.

18. Sanders C, Donovan JL, Dieppe PA. Unmet need for joint replacement: a qualitative investigation of barriers to treatment among individuals with severe pain and disability of the hip and knee. Rheumatology (Oxford) 2004; 43(3): 353-357.

19. Pound P, Gompertz P, Ebrahim S. Illness in the context of older age: the case of stroke. Sociol Health Illness 1998; 20(4): 489-506.

20. Koch LH. Help-seeking behaviors of women with urinary incontinence: an integrative literature review. J Midwifery Womens Health 2006; 51(6): e39-e44.

21. Spruit MA, Vanderhoven-Augustin I, Janssen PP, Wouters EF. Integration of pulmonary rehabilitation in COPD. Lancet 2008 . 371(9606): 12-13.

22. Clini EM, Ambrosino N. Nonpharmacological treatment and relief of symptoms in COPD. Eur Respir J 2008; 32(1): 218-228. 